\title{
Monolithic ATF MiniFuel Sample Capsules Ready for HFIR Insertion
}

Nuclear Technology

Research and Development

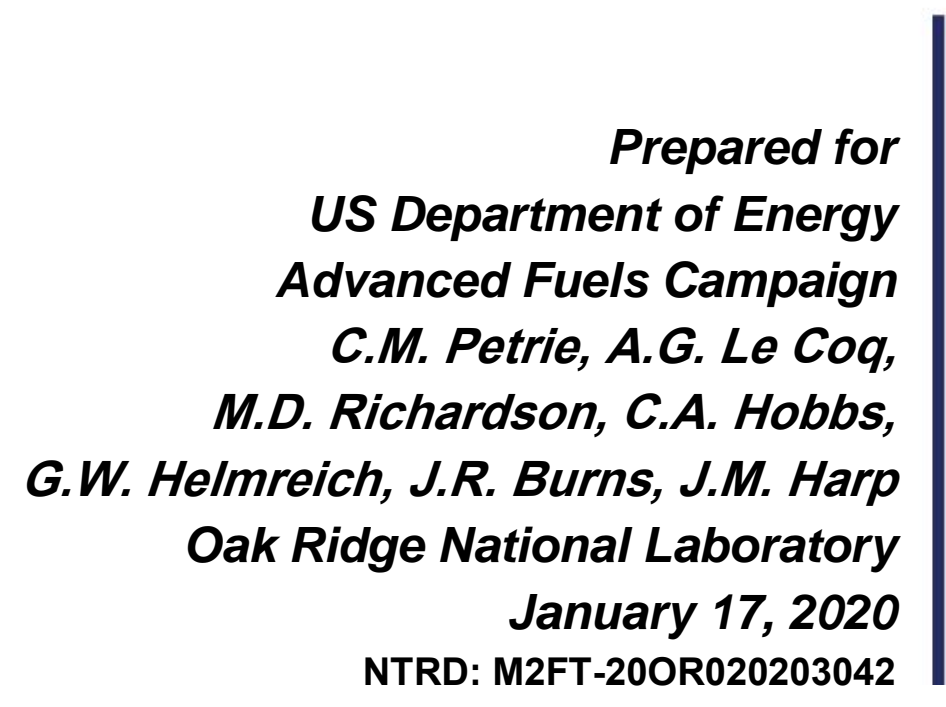





\section{DISCLAIMER}

This information was prepared as an account of work sponsored by an agency of the U.S. Government. Neither the U.S. Government nor any agency thereof, nor any of their employees, makes any warranty, expressed or implied, or assumes any legal liability or responsibility for the accuracy, completeness, or usefulness, of any information, apparatus, product, or process disclosed, or represents that its use would not infringe privately owned rights. References herein to any specific commercial product, process, or service by trade name, trade mark, manufacturer, or otherwise, does not necessarily constitute or imply its endorsement, recommendation, or favoring by the U.S. Government or any agency thereof. The views and opinions of authors expressed herein do not necessarily state or reflect those of the U.S. Government or any agency thereof. 



\section{SUMMARY}

Several advanced nuclear fuel concepts are being considered throughout the nuclear industry.

Implementation of these concepts could increase accident tolerance or enhance performance beyond the capabilities of the $\mathrm{UO}_{2}$-based nuclear fuel currently in use. Qualification and deployment of any new fuel requires rigorous irradiation testing to demonstrate performance under representative normal and offnormal operating conditions. The traditional approach for qualifying new fuels requires exhaustive execution of many integral fuel tests. However, due to the long timeframe for executing these integral tests and the limited number of available materials test reactors, this approach is becoming impractical. To accelerate fuel qualification, Oak Ridge National Laboratory developed the MiniFuel irradiation vehicle for use in conducting accelerated separate effects irradiation testing of a wide range of nuclear fuel materials in the High Flux Isotope Reactor (HFIR). The first MiniFuel irradiations performed in the facility tested sol gel-derived uranium nitride kernels and tristructural isotropic (TRISO)-coated particle fuels. This report describes the preparation and assembly of the first set of monolithic MiniFuel irradiations conducted to support accident-tolerant fuel (ATF) development and accelerated fuel qualification. Two irradiation targets containing a variety of $\mathrm{UO}_{2}$ and $\mathrm{U}_{3} \mathrm{Si}_{2}$ disk fuel specimens were fabricated and assembled for irradiation to burnups of 8-10 and $28-40 \mathrm{MWd} / \mathrm{kg} \mathrm{U}$. The target irradiation temperature is $450-550^{\circ} \mathrm{C}$. Irradiation of $\mathrm{U}_{3} \mathrm{Si}_{2}$ will provide new data regarding the irradiation performance of a candidate ATF to complement current ATF-1 integral experiments being performed in the Advanced Test Reactor. $\mathrm{UO}_{2}$ samples were included as a reference so that the results from the MiniFuel experiments can be compared with the extensive $\mathrm{UO}_{2}$ fuel performance database. The monolithic MiniFuel capsules were successfully assembled, welded, and tested per HFIR requirements and are ready for insertion into the reactor. Pictures of the assembly process are included in this report. The experiment is planned for insertion into the HFIR during cycle 487 in April 2020. 
Monolithic ATF MiniFuel Sample Capsules Ready for HFIR Insertion 


\section{CONTENTS}

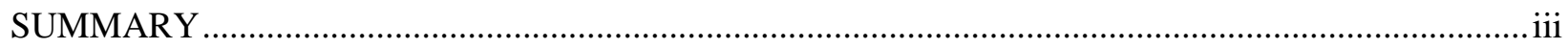

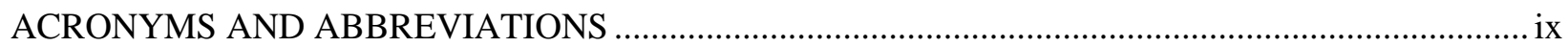

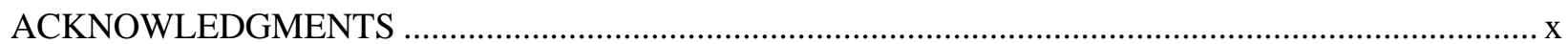

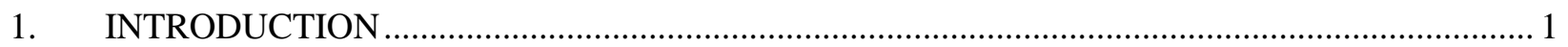

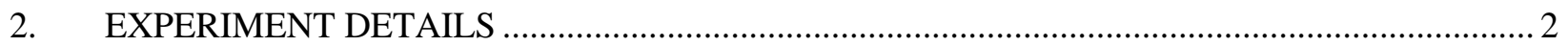

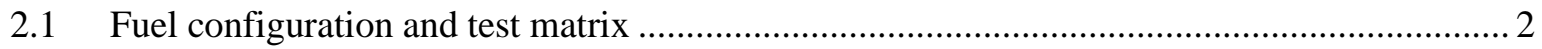

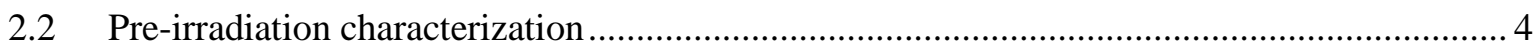

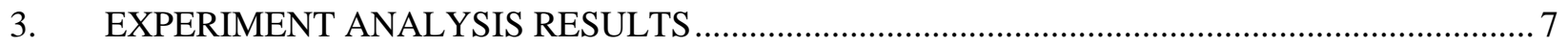

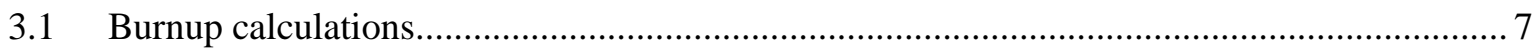

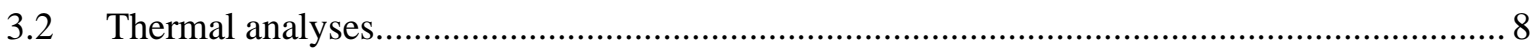

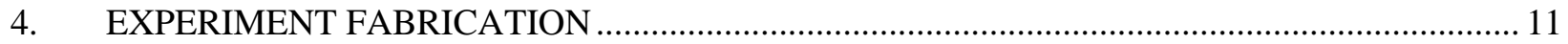

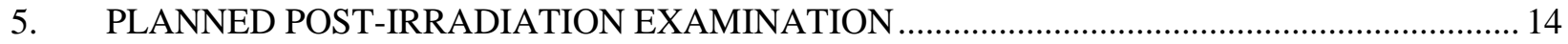

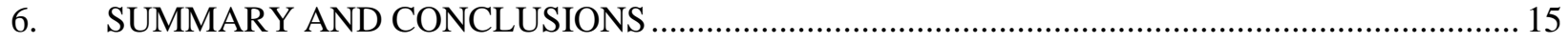

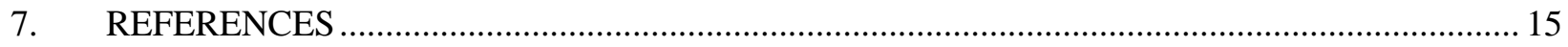

APPENDIX A. FABRICATION DOCUMENTATION FOR EXPERIMENTS …................................ A-1 


\section{FIGURES}

Figure 1. MiniFuel experiment configuration showing sealed capsules with disk specimens (this work), as well as other potential fuel configurations. This figure was reused with

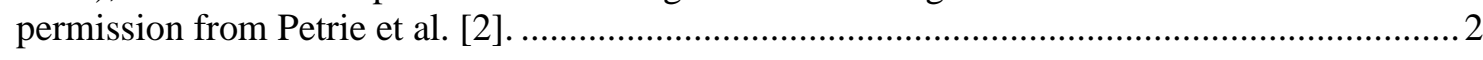

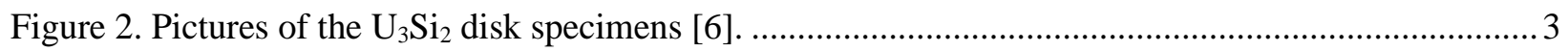

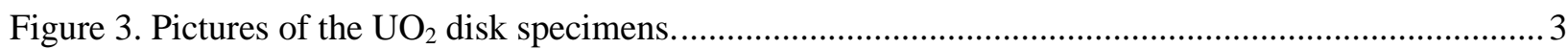

Figure 4. Percent theoretical densities for the $\mathrm{UO}_{2}$ specimens determined using geometric measurements (ORNL Geo), XCT, and a 3D Keyence optical profilometer (Keyence). Only the last two digits of the specimen IDs are shown.

Figure 5. Percent theoretical densities for the $\mathrm{U}_{3} \mathrm{Si}_{2}$ specimens determined using geometric measurements (ORNL Geo and LANL Geo), immersion (LANL Immersion), XCT, and a 3D Keyence optical profilometer (Keyence). Only the last two digits of the specimen IDs are shown. Keyence measurements for specimens 52 and 54 are off scale and clearly nonphysical (>100\% theoretical density).

Figure 6. Calculated $\mathrm{U}_{3} \mathrm{Si}_{2}$ fuel fission rate (solid lines) and burnup (dashed lines) vs. irradiation time or number of HFIR cycles for the first 4 cycles of irradiation in capsules with RAS IDs $121,123,124$, and $126 . \mathrm{R}=$ radial target position, $\mathrm{A}=$ axial target position, and $\mathrm{S}$ = subcapsule (or capsule) position

Figure 7. Predicted temperature contours (in ${ }^{\circ} \mathrm{C}$ ) for a $\mathrm{U}_{3} \mathrm{Si}_{2}$ disk specimen in position RAS 123 at the end of 4 cycles of irradiation. Results show the capsule assembly (top) and the fuel specimen (bottom)

Figure 8. Calculated variations in the average $\mathrm{U}_{3} \mathrm{Si}_{2}$ disk fuel temperatures (top) and $\mathrm{TM}$ temperatures (bottom) at beginning of cycle (BOC) and end of cycle (EOC) for cycles 1,4 , and 12 .

Figure 9. Components for one $\mathrm{UO}_{2}$-fueled capsule.

Figure 10. Loading of a $\mathrm{UO}_{2}$ disk specimen (a) into a cup inside the bottom loading fixture (b).

Figure 11. Filler placed over cup assembly and turned upside down while applying pressure with top loading fixture (a), bottom loading fixture removed (b), and capsule is turned upside down and placed over the tube and cup assembly (c).

Figure 12. Loading TMs (a), insulators (b), and endcaps (c) into a capsule.

Figure 13. All 12 capsules prepped for electron beam welding (a); close-up views of a single capsule before (b) and after (c) welding. 


\section{TABLES}

Table 1. Test matrix for $\mathrm{U}_{3} \mathrm{Si}_{2}$ and $\mathrm{UO}_{2}$ monolithic disk irradiation.................................................... 4

Table 2. Pre-irradiation mass and dimensional measurements of specimens. ............................................5 
Monolithic ATF MiniFuel Sample Capsules Ready for HFIR Insertion 


\section{ACRONYMS AND ABBREVIATIONS}

$\begin{array}{ll}\text { AFC } & \text { Advanced Fuels Campaign } \\ \text { ATF } & \text { accident tolerant fuel } \\ \text { BOC } & \text { beginning of cycle } \\ \text { DOE-NE } & \text { US Department of Energy, Office of Nuclear Energy } \\ \text { EOC } & \text { end of cycle } \\ \text { HFIR } & \text { High Flux Isotope Reactor } \\ \text { IFEL } & \text { Irradiated Fuels Examination Laboratory } \\ \text { LANL } & \text { Los Alamos National Laboratory } \\ \text { ORNL } & \text { Oak Ridge National Laboratory } \\ \text { PIE } & \text { post-irradiation examination } \\ \text { SiC } & \text { silicon carbide } \\ \text { TM } & \text { temperature monitor } \\ \mathrm{TRISO}_{\mathrm{UN}} & \text { tristructural isotropic } \\ \mathrm{UO}_{2} & \text { uranium nitride } \\ \mathrm{U}_{3} \mathrm{Si}{ }_{2} & \text { uranium dioxide } \\ \mathrm{XCT} & \text { uranium silicide }\end{array}$




\section{ACKNOWLEDGMENTS}

This work was supported by the US Department of Energy Office of Nuclear Energy (DOE-NE) Advanced Fuels Campaign (AFC). Neutron irradiation in the High Flux Isotope Reactor (HFIR) is made possible by the Office of Basic Energy Sciences, US DOE. The report was authored by UT-Battelle under Contract No. DE-AC05-00OR22725 with the US DOE. Alicia Raftery and David Bryant performed most of the capsule assembly work. Doug Kyle and Alan Frederick performed the welding of the capsules and Eric Vidal performed the non-destructive examination of the capsules. 


\section{INTRODUCTION}

Any new nuclear fuel concept must undergo rigorous irradiation testing so that a comprehensive knowledge base of fuel performance can be built to ultimately make the regulatory case to license the fuel. This has traditionally been accomplished by performing exhaustive integral fuel testing, including full- or near-full-scale testing under environmental conditions closely matching those of the intended application [1]. However, this logical approach presents some challenges that must be addressed. First, detailed analyses are required to properly design and characterize a full integral fuel test. This requirement requires significant time and cost when qualifying new fuels. Second, because integral tests are performed under prototypic conditions, the fission rate must also be matched to that of the intended application. This means that the time required to reach end-of-life burnup will take at least as long as the fuel would operate in its final application, and likely longer, because most test reactors operate at a much lower capacity factor than commercial reactors. Third, it is difficult to isolate a single fuel performance variable and develop a thorough scientific understanding of fuel performance during integral testing with so many interdependent variables. This lack of scientific understanding makes it extremely difficult to extend the use of a fuel that was tested under a specific set of conditions to other applications with different environmental conditions.

To accelerate the timeframe to qualify new nuclear fuels, a new, two-part approach is being developed that relies on modern modeling and simulation tools to rapidly identify parameters with a high impact on fuel performance and a large uncertainty. This data will allow for proper prioritization of targeted irradiation experiments. The second part of the approach to accelerated fuel qualification is to leverage separate effects irradiation tests. These tests will be designed specifically to isolate the most impactful fuel performance variables and provide experimental data to fill these critical gaps in the fuel performance models. Accordingly, Oak Ridge National Laboratory (ORNL) has developed and deployed a new experimental capability in the High Flux Isotope Reactor (HFIR): the MiniFuel irradiation vehicle [2-4]. This irradiation testing capability allows for highly accelerated burnup accumulation with minimal coupling between the fission rate and the fuel temperature. This is accomplished by reducing the volume of the fuel and packaging the miniature fuel specimens inside individually sealed capsules. The properly designed capsule ensures that the total nuclear heat generated inside each capsule is dominated by gamma heating in the structural components as opposed to fission heating in the fuel. This allows for a flexible irradiation vehicle that can accommodate a wide range of fuel compositions, enrichments, and even geometries. The small size of the fuel also greatly reduces temperature gradients, which allows for nearisothermal conditions.

The MiniFuel experiment vehicle has been successfully used to test a variety of sol gel-derived uranium nitride kernels and tristructural isotropic (TRISO)-coated particle fuels [5]. This document describes the successful assembly of the first set of MiniFuel targets containing monolithic fuel specimens that more closely resemble traditional $\mathrm{UO}_{2}$ pellets. Two irradiation targets - each containing $\mathrm{U}_{3} \mathrm{Si}_{2}$ and reference $\mathrm{UO}_{2}$ fuel disks - will be tested to a low $(\sim 8-10 \mathrm{MWd} / \mathrm{kg} \mathrm{U})$ and moderate $(\sim 28-40$ $\mathrm{MWd} / \mathrm{kg} \mathrm{U}$ ) burnup at temperatures in the range of $450-550^{\circ} \mathrm{C}$. This report describes the fuel configuration and test matrix, the expected fuel burnup and temperature profiles, pre-irradiation characterization, experiment assembly, and plans for post-irradiation examination. 


\section{EXPERIMENT DETAILS}

\subsection{Fuel configuration and test matrix}

The primary differences between the first MiniFuel experiments and the experiments described in this report are the fuel geometry and composition. The planned experiments discussed herein will test monolithic $\mathrm{U}_{3} \mathrm{Si}_{2}$ disks fabricated by Los Alamos National Laboratory (LANL), along with $\mathrm{UO}_{2}$ disks fabricated at ORNL that will serve as a reference. The experiment geometry showing disk specimens contained inside sealed capsules is shown in Figure 1. The experiments described in this work will be inserted into two different baskets located in different inner small vertical experiment facilities in the permanent reflector of HFIR. Each target will be positioned in radial target position 2, facing away from the core centerline, and axial target position 1 , at the vertical midplane of the core. Images of the $\mathrm{U}_{3} \mathrm{Si}_{2}$ and $\mathrm{UO}_{2}$ disk specimens are shown in Figure 2 and Figure 3, respectively. The test matrix is summarized in Table 1.

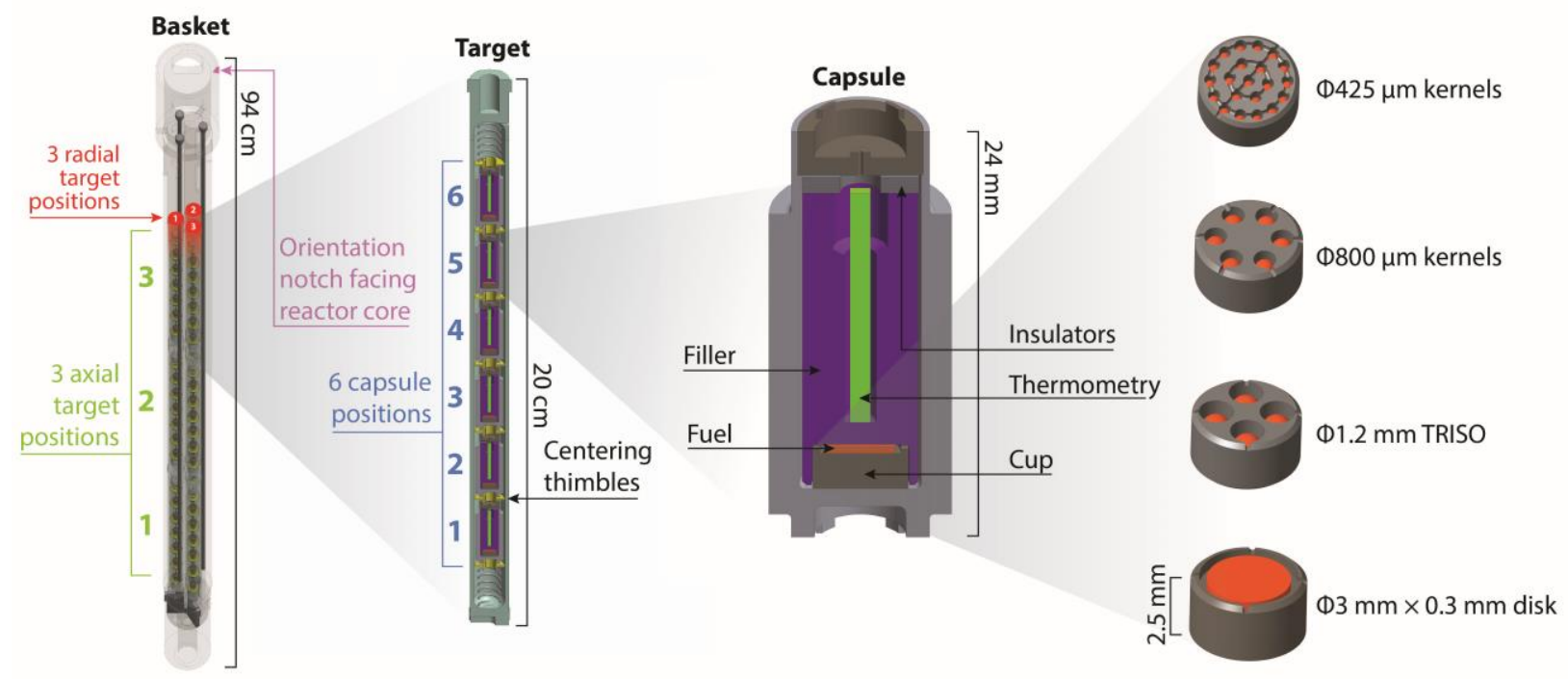

Figure 1. MiniFuel experiment configuration showing sealed capsules with disk specimens (this work), as well as other potential fuel configurations. This figure was reused with permission from Petrie et al. [2]. 

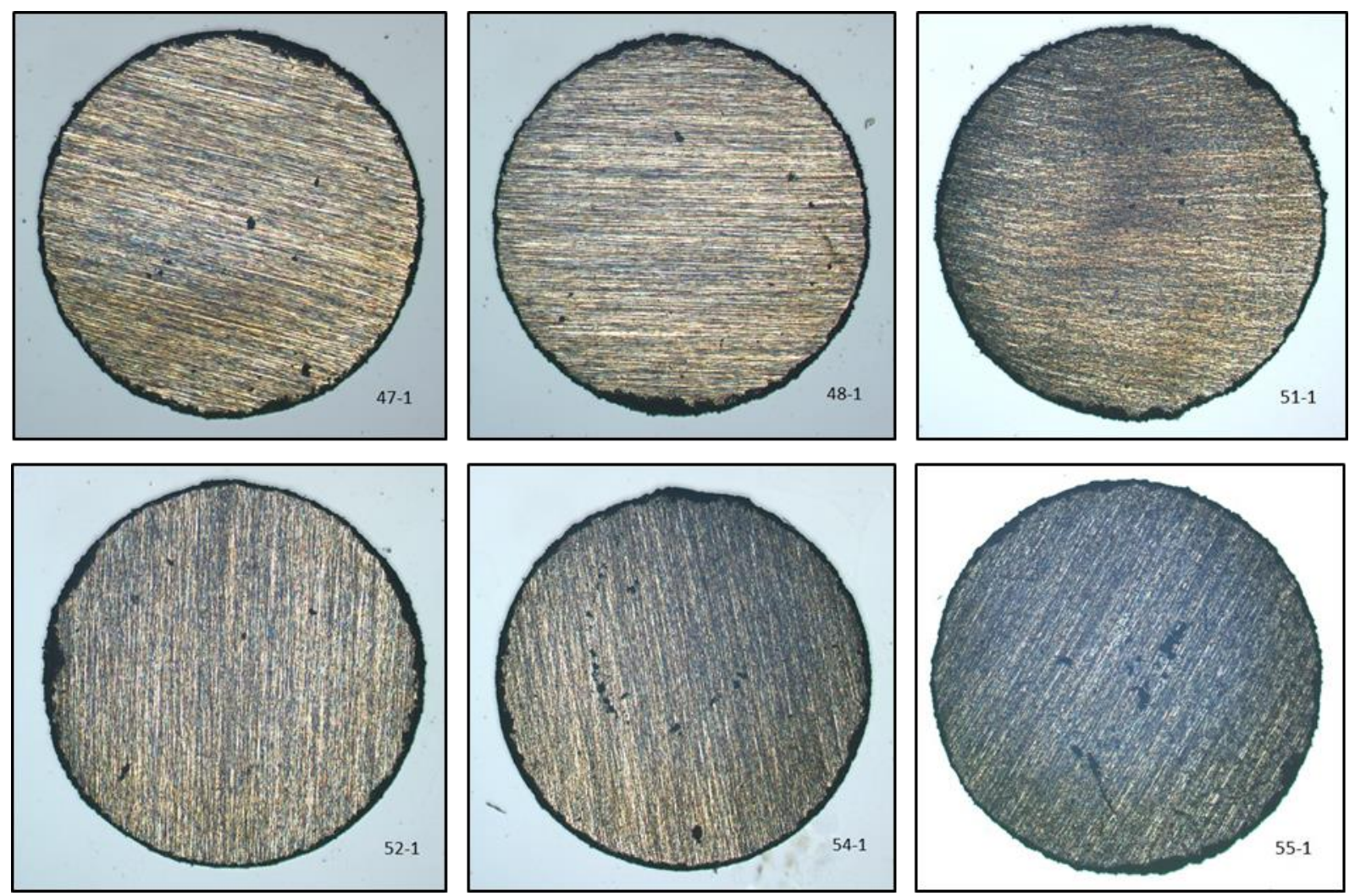

Figure 2. Pictures of the $\mathrm{U}_{3} \mathrm{Si}_{2}$ disk specimens [6].
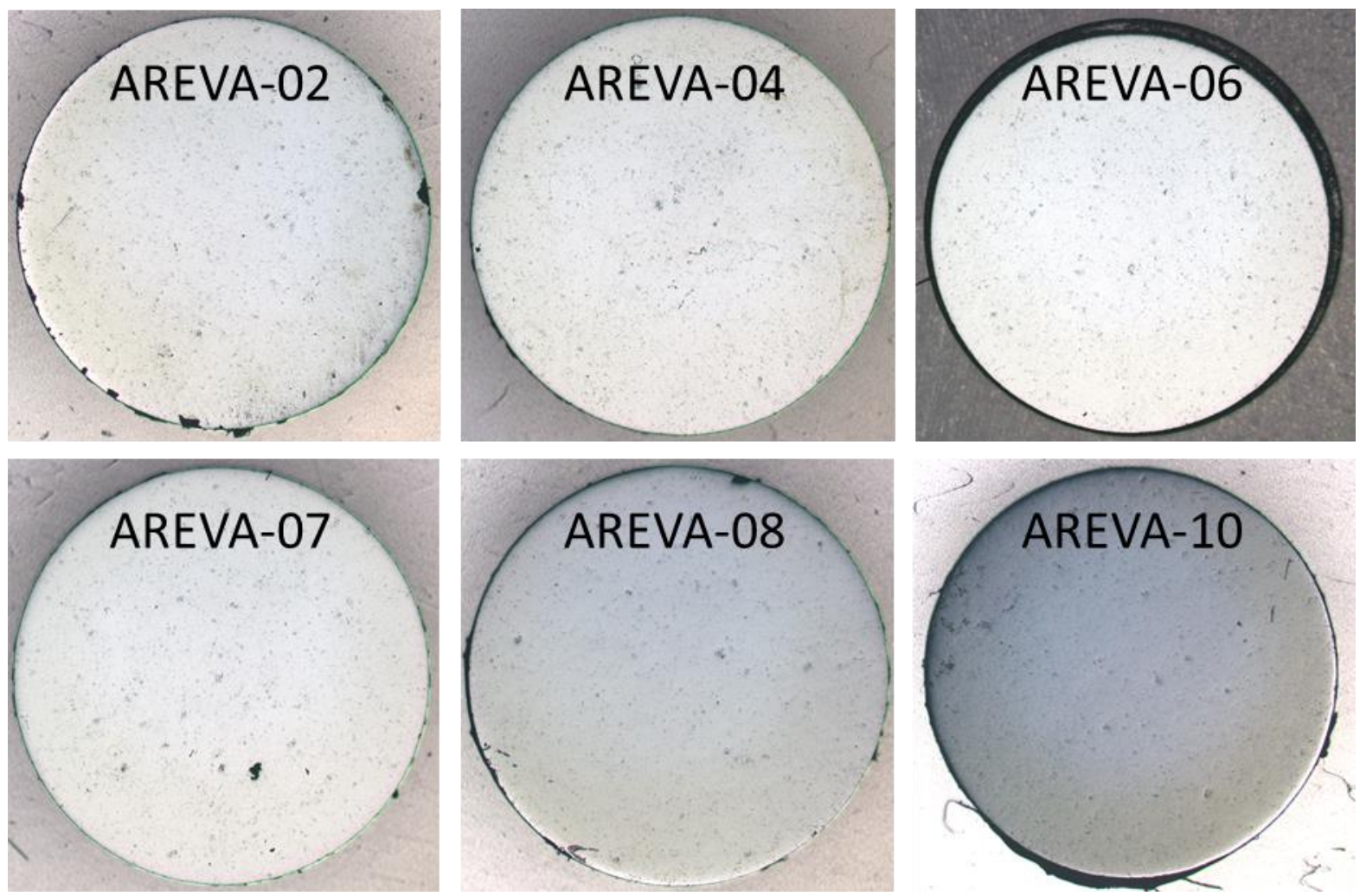

Figure 3. Pictures of the $\mathrm{UO}_{2}$ disk specimens. 
Table 1. Test matrix for $\mathrm{U}_{3} \mathrm{Si}_{2}$ and $\mathrm{UO}_{2}$ monolithic disk irradiation.

\begin{tabular}{|c|c|c|c|c|c|}
\hline $\begin{array}{c}\text { Target } \\
\text { ID }\end{array}$ & $\begin{array}{l}\text { Fuel } \\
\text { form }\end{array}$ & $\begin{array}{c}\text { Fuel sample } \\
\text { ID }\end{array}$ & $\begin{array}{c}{ }^{235} \mathrm{U} \\
\text { enrichment }\end{array}$ & $\begin{array}{l}\text { Target } \\
\text { burnup }\end{array}$ & Target temperature \\
\hline \multirow{6}{*}{ LA01 } & \multirow{3}{*}{$\mathrm{UO}_{2}$} & AREVA-02 & \multirow{3}{*}{$0.35 \mathrm{wt} \%$} & \multirow{6}{*}{$\begin{array}{c}8-10 \\
\mathrm{MWd} / \mathrm{kg} \mathrm{U}\end{array}$} & \multirow{12}{*}{$450-550^{\circ} \mathrm{C}$} \\
\hline & & AREVA-04 & & & \\
\hline & & AREVA-06 & & & \\
\hline & \multirow{3}{*}{$\mathrm{U}_{3} \mathrm{Si}_{2}$} & $35-\mathrm{P}-19-47$ & \multirow{3}{*}{$0.19 \mathrm{wt} \%$} & & \\
\hline & & $35-\mathrm{P}-19-48$ & & & \\
\hline & & $35-\mathrm{P}-19-51$ & & & \\
\hline \multirow{6}{*}{ LB02 } & \multirow{3}{*}{$\mathrm{UO}_{2}$} & AREVA-07 & \multirow{3}{*}{$0.35 \mathrm{wt} \%$} & \multirow{6}{*}{$\begin{array}{c}28-40 \\
\mathrm{MWd} / \mathrm{kg} \mathrm{U}\end{array}$} & \\
\hline & & AREVA-08 & & & \\
\hline & & AREVA-10 & & & \\
\hline & \multirow{3}{*}{$\mathrm{U}_{3} \mathrm{Si}_{2}$} & $35-\mathrm{P}-19-52$ & \multirow{3}{*}{$0.19 \mathrm{wt} \%$} & & \\
\hline & & $35-\mathrm{P}-19-54$ & & & \\
\hline & & $35-\mathrm{P}-19-55$ & & & \\
\hline
\end{tabular}

\subsection{Pre-irradiation characterization}

Pre-irradiation characterization included measurements of diameter, thickness, mass, and density (see Table 2). Additional unirradiated samples were preserved so that the irradiated and pre-irradiated microstructures can be compared. Dimensions for the $\mathrm{U}_{3} \mathrm{Si}_{2}$ specimens were measured independently by ORNL and LANL. At ORNL, diameter measurements were performed using calipers with $0.01 \mathrm{~mm}$ precision. Thickness measurements were performed using a micrometer with $0.001 \mathrm{~mm}$ precision. All samples were weighed using a scale. To determine density, volumes were calculated at ORNL using three different methods: (1) a simple geometric calculation using the measured diameter and thickness, (2) X-ray computed tomography (XCT) [7, 8], and (3) a wide area 3D optical profilometer (Keyence VR5000). Geometric measurements performed at ORNL and LANL are labeled "ORNL Geo" and "LANL Geo," respectively. Measurements made with the Keyence optical profilometer are labeled "Keyence."

Dimensions of the $\mathrm{UO}_{2}$ specimens were measured after pressing and sintering but before grinding. These pre-grinding measurements were used to determine the specimens' geometric densities, because the larger specimen thickness could be measured more accurately. The reduced geometric accuracy post-grinding is evident when comparing the uncertainties in the geometric densities determined by ORNL for the $\mathrm{U}_{3} \mathrm{Si}_{2}$ specimens, which were measured after grinding, to the geometric densities for the $\mathrm{UO}_{2}$ specimens, which were measured before grinding. It is possible that the outer regions of the specimens were more porous and that grinding these regions resulted in increased densities compared to the densities determined before grinding. All uncertainties are $\pm 2 \sigma(95 \%$ confidence interval). The geometric uncertainties were determined via error propagation of the uncertainties in the measured diameters and thicknesses. Uncertainties are not reported for the Keyence measurements. LANL densities were determined geometrically after the specimens were ground to their final geometries using immersion density pre-grinding, although no uncertainties were reported for any of the measurements [6].

Figure 4 and Figure 5 show the percent theoretical densities determined for each $\mathrm{UO}_{2}$ and $\mathrm{U}_{3} \mathrm{Si}_{2}$ specimen, respectively, using different techniques. The theoretical densities were assumed to be 10.96 
and $12.20 \mathrm{~g} / \mathrm{cm}^{3}$, respectively [9]. With a few exceptions, geometric measurements, XCT, and Keyence measurements generally give consistent volumes for the $\mathrm{UO}_{2}$ specimens. Some XCT measurements predict densities $>100 \%$ theoretical density, although the uncertainties are on the order of $5 \%$. For the $\mathrm{U}_{3} \mathrm{Si}_{2}$ specimens, the Keyence measurements for specimens 52 and 54 are clearly nonphysical, with values close to $150 \%$ of theoretical density. It appears that the profilometer did not capture the thickness of these discs properly. The remaining densities are generally consistent across the various measurement techniques, although it is difficult to assess some of the data for which uncertainties are not reported. Geometric uncertainties are significantly greater for the $\mathrm{U}_{3} \mathrm{Si}_{2}$ specimens than the $\mathrm{UO}_{2}$ specimens. This is due to larger variations in $\mathrm{U}_{3} \mathrm{Si}_{2}$ specimen thickness compared to the thickness variations in the $\mathrm{UO}_{2}$ specimens. Efforts to resolve inconsistencies between the various techniques and to select the most appropriate techniques for pre- and post-irradiation density measurements are ongoing.

Table 2. Pre-irradiation mass and dimensional measurements of specimens.

\begin{tabular}{|c|c|c|c|c|c|c|c|c|c|}
\hline \multirow{2}{*}{$\begin{array}{c}\text { Fuel sample } \\
\text { ID }\end{array}$} & \multirow{2}{*}{$\begin{array}{l}\text { Fuel } \\
\text { form }\end{array}$} & \multirow{2}{*}{ Mass (g) } & \multirow{2}{*}{$\begin{array}{l}\text { Diameter } \\
(\mathbf{m m})\end{array}$} & \multirow{2}{*}{$\begin{array}{c}\text { Thickness } \\
(\mathbf{m m})\end{array}$} & \multicolumn{5}{|c|}{ Density (percent theoretical) } \\
\hline & & & & & $\begin{array}{c}\text { ORNL } \\
\text { Geo }\end{array}$ & \begin{tabular}{|c|} 
LANL \\
Geo \\
\end{tabular} & $\begin{array}{c}\text { LANL } \\
\text { Immersion }\end{array}$ & XCT & Keyence \\
\hline AREVA-02 & \multirow{6}{*}{$\mathrm{UO}_{2}$} & 0.0251 & 3.28 & 0.271 & $96.1 \pm 1.2$ & N/A & N/A & $96.4 \pm 5.6$ & 94.6 \\
\hline AREVA-04 & & 0.0262 & 3.23 & 0.273 & $93.3 \pm 1.2$ & N/A & N/A & $102.3 \pm 4.3$ & 94.7 \\
\hline AREVA-06 & & 0.0306 & 3.28 & 0.324 & $93.8 \pm 1.2$ & N/A & N/A & $99.5 \pm 5.9$ & 95.5 \\
\hline AREVA-07 & & 0.0326 & 3.28 & 0.350 & $92.1 \pm 1.1$ & N/A & N/A & $95.4 \pm 4.1$ & 96.1 \\
\hline AREVA-08 & & 0.0300 & 3.28 & 0.333 & $94.3 \pm 1.2$ & N/A & N/A & $97.2 \pm 4.4$ & 94.1 \\
\hline AREVA-10 & & 0.0305 & 3.29 & 0.342 & $93.5 \pm 1.1$ & N/A & N/A & $97.6 \pm 4.4$ & 95.0 \\
\hline $35-\mathrm{P}-19-47$ & \multirow{6}{*}{$\mathrm{U}_{3} \mathrm{Si}_{2}$} & 0.0200 & 2.807 & 0.276 & $96.1 \pm 2.0$ & 93.5 & 87.6 & $93.6 \pm 3.6$ & 89.9 \\
\hline 35-P-19-48 & & 0.0186 & 2.807 & 0.255 & $96.8 \pm 7.7$ & 94.3 & 89.5 & $89.3 \pm 3.3$ & 90.3 \\
\hline 35-P-19-51 & & 0.0173 & 2.810 & 0.235 & $97.2 \pm 5.0$ & 92.9 & 93.2 & $89.9 \pm 1.8$ & 91.4 \\
\hline 35-P-19-52 & & 0.0180 & 2.827 & 0.245 & $96.0 \pm 2.2$ & 95.5 & 91.1 & $101.3 \pm 2.4$ & 149.9 \\
\hline 35-P-19-54 & & 0.0204 & 2.847 & 0.277 & $95.0 \pm 2.6$ & 93.2 & 90.5 & $95.3 \pm 5.4$ & 147.2 \\
\hline $35-\mathrm{P}-19-55$ & & 0.0189 & 2.813 & 0.268 & $93.0 \pm 5.2$ & 92.9 & 90.6 & $89.1 \pm 4.1$ & 91.0 \\
\hline
\end{tabular}




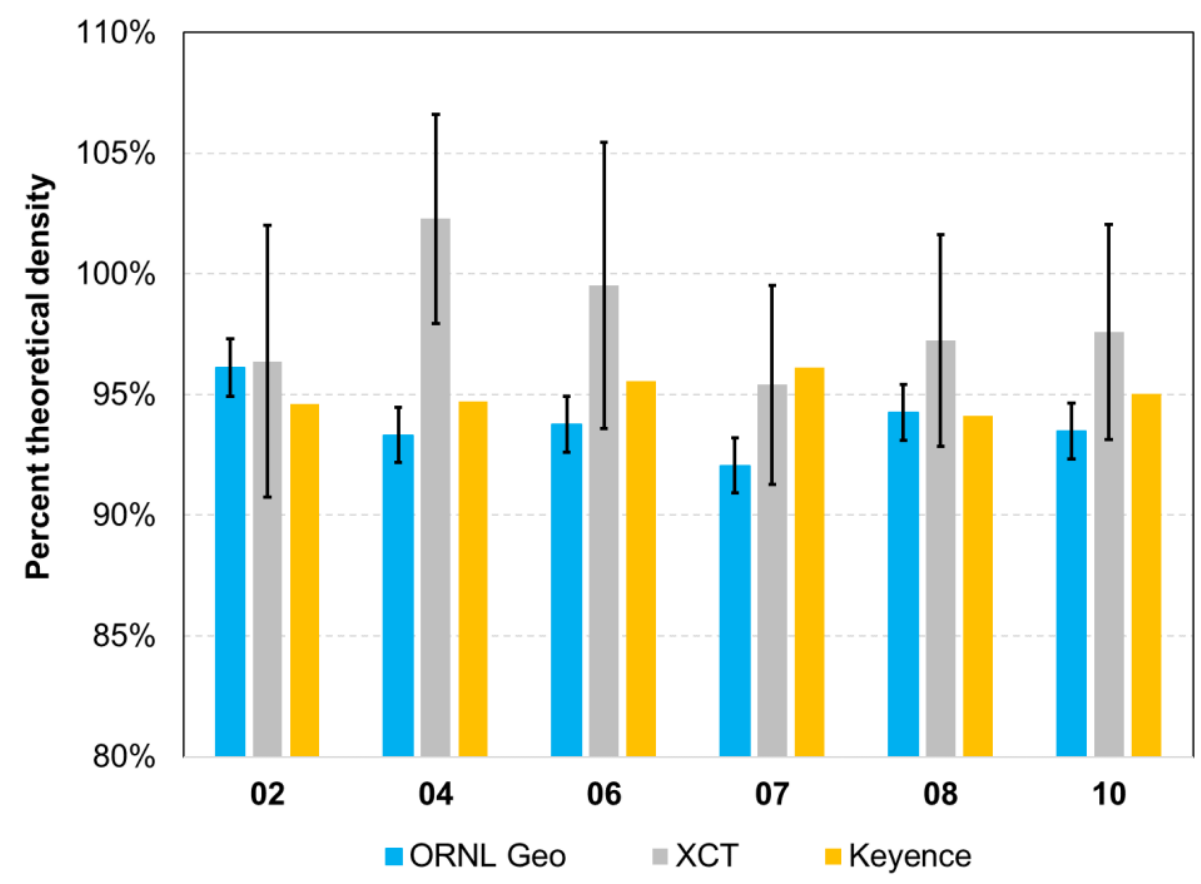

Figure 4. Percent theoretical densities for the $\mathrm{UO}_{2}$ specimens determined using geometric measurements (ORNL Geo), XCT, and a 3D Keyence optical profilometer (Keyence). Only the last two digits of the specimen IDs are shown.

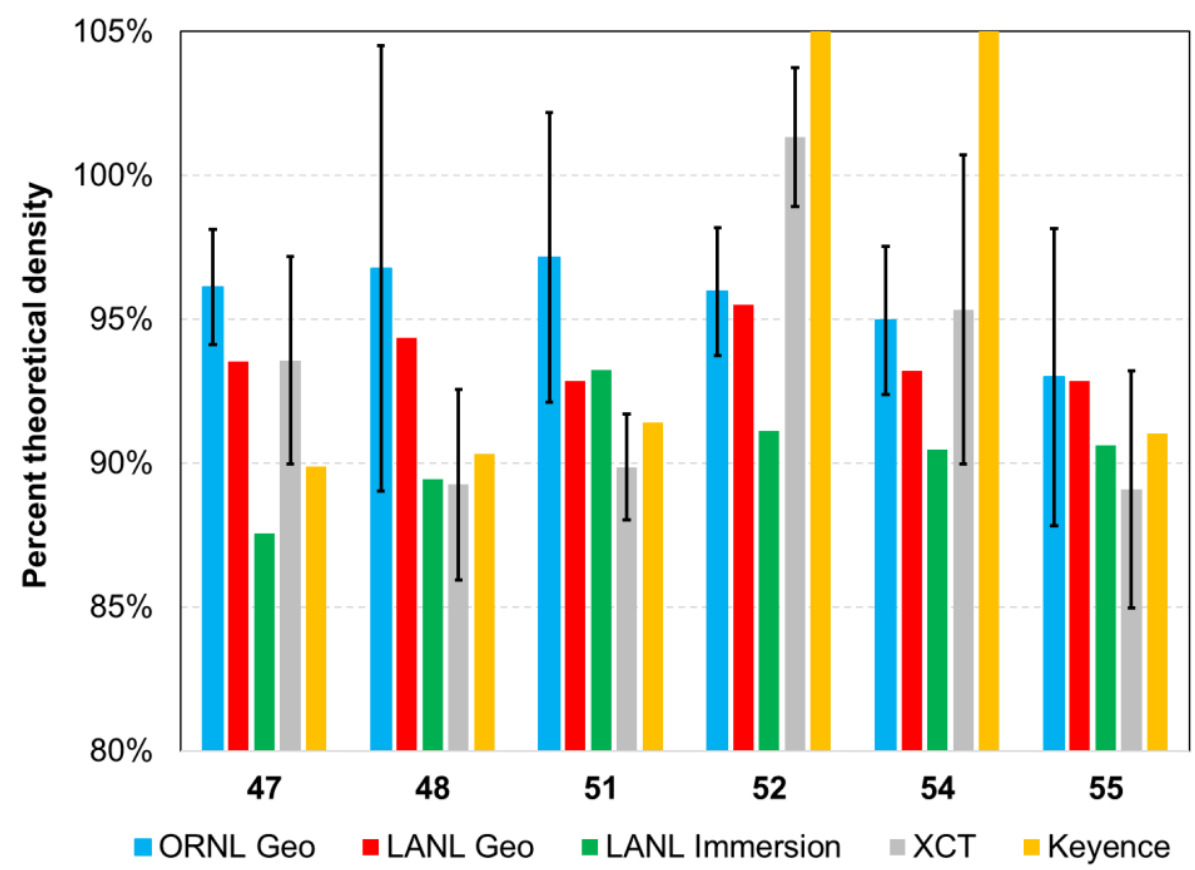

Figure 5. Percent theoretical densities for the $\mathrm{U}_{3} \mathrm{Si}_{2}$ specimens determined using geometric measurements

(ORNL Geo and LANL Geo), immersion (LANL Immersion), XCT, and a 3D Keyence optical profilometer (Keyence). Only the last two digits of the specimen IDs are shown. Keyence measurements for specimens 52 and 54 are off scale and clearly nonphysical (>100\% theoretical density). 


\section{EXPERIMENT ANALYSIS RESULTS}

\subsection{Burnup calculations}

Fuel fission rates and burnup were calculated by coupling the MCNP and ORIGEN codes. Over time, the initial ${ }^{235} \mathrm{U}$ is burned, but breeding of fissile Pu isotopes allows for continued burnup accumulation with a fission rate that approaches an equilibrium after approximately 6 cycles of irradiation. Previous MiniFuel irradiations were inserted into the two radial target positions that face the center of the HFIR core. The monolithic fuel irradiations described in this report will be placed in the third radial position that faces away from the HFIR core. All targets will be placed at the axial midplane of the core. Moving radially away from the center of the core results in a slight reduction in the fission rates. Figure 6 shows fuel fission heating rates and accumulated burnup vs. the number of HFIR cycles for $\mathrm{U}_{3} \mathrm{Si}_{2}$ specimens fabricated from depleted uranium $\left(0.22 \%{ }^{235} \mathrm{U}\right)$. At this writing, burnup simulations have been performed for 4 cycles of irradiation. Simulations for up to 12 subsequent cycles are ongoing. The burnup, which is expressed per unit mass of uranium, is identical for $\mathrm{UO}_{2}$ and $\mathrm{U}_{3} \mathrm{Si}_{2}$ specimens. Results are shown for various capsule positions within the irradiation target. The capsule positions are designated as follows:

- $\quad$ radial target position $=\mathrm{R}$,

- $\quad$ axial target position $=\mathrm{A}$, and

- $\quad$ subcapsule or capsule position $=\mathrm{S}$.

RAS positions 121, 123, 124, and 126 are shown in Figure 6, covering the entire range of the irradiation target, from bottom to top. Based on these results, it is anticipated that after 4 cycles, a burnup of approximately $8 \mathrm{MWd} / \mathrm{kg} \mathrm{U}$ will be reached. Because the fission rates typically approach an equilibrium after $\sim 6$ cycles [2], it is expected that after 12 cycles of irradiation, the total burnup will be approximately $28 \mathrm{MWd} / \mathrm{kg} \mathrm{U}$. The final burnup for target discharge will be determined by as-run HFIR operations and programmatic goals for accumulating burnup that is comparable to other experiments. 


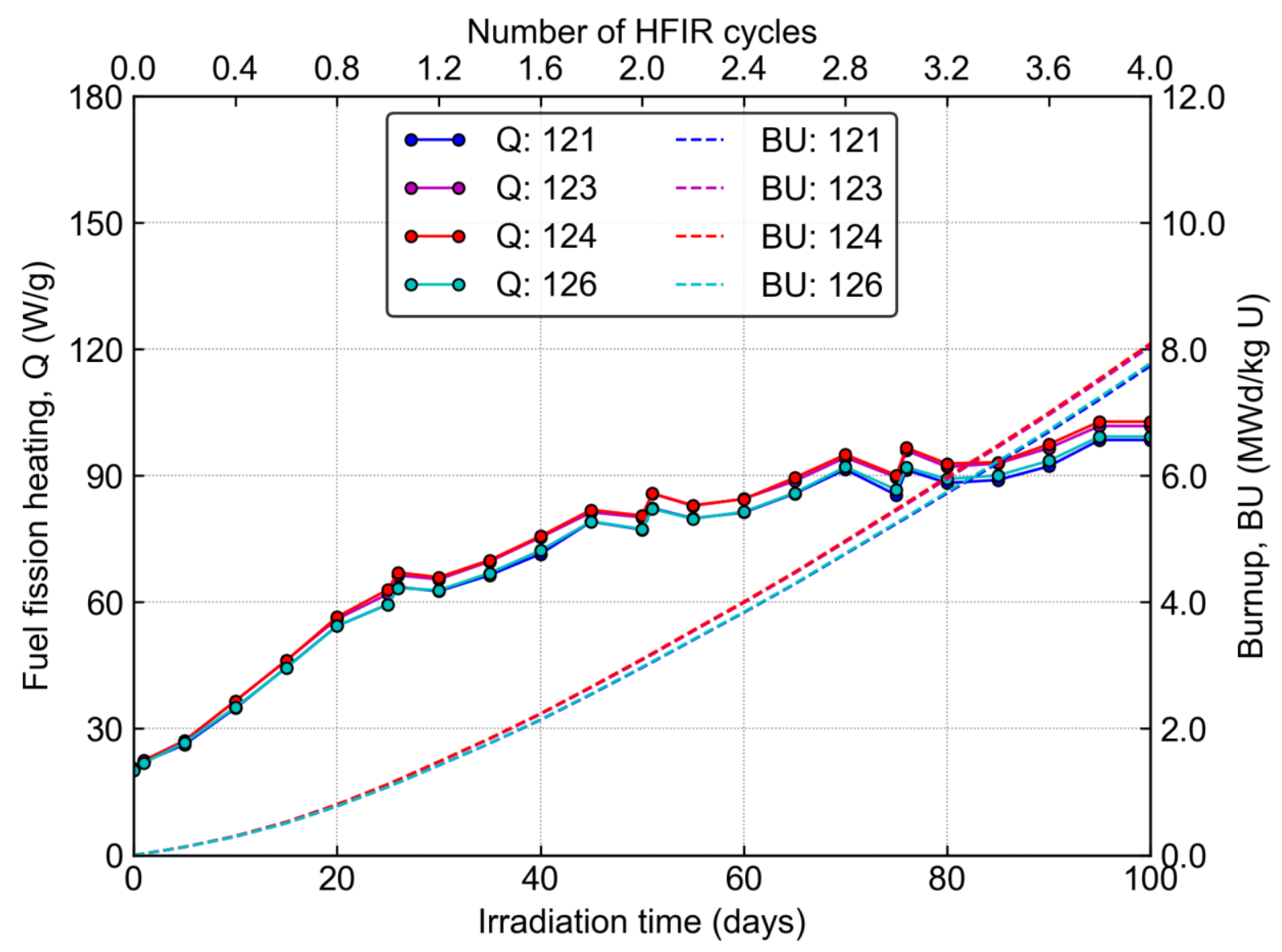

Figure 6. Calculated $\mathrm{U}_{3} \mathrm{Si}_{2}$ fuel fission rate (solid lines) and burnup (dashed lines) vs. irradiation time or number of HFIR cycles for the first 4 cycles of irradiation in capsules with RAS IDs 121, 123, 124, and

126. $\mathrm{R}=$ radial target position, $\mathrm{A}=$ axial target position, and $\mathrm{S}=$ subcapsule (or capsule) position.

\subsection{Thermal analyses}

Figure 7 shows temperature contours for a capsule containing $\mathrm{U}_{3} \mathrm{Si}_{2}$ fuel disks. These temperatures were calculated at the end of 4 cycles of irradiation in position RAS 123. Temperature is controlled by choosing the size of the gas gap between the capsules and the target housing, as well as the composition of the fill gas, which was chosen to be a $40.5 \% \mathrm{He}-\mathrm{Ar}$ balance mixture. The interiors of the capsules are filled with helium. The diameters of the capsules are nominally $9.20 \mathrm{~mm}$, resulting in a nominal gas gap of $0.86 \mathrm{~mm}(10.06 \mathrm{~mm}$ inner target diameter). The average fuel temperature is approximately $542^{\circ} \mathrm{C}$. The temperature gradients in the fuel are minimal $\left(4^{\circ} \mathrm{C}\right)$ because of the small fuel size. The passive $\mathrm{SiC}$ temperature monitors (TMs) have an average temperature of approximately $514^{\circ} \mathrm{C}$ $\left(\sim 30^{\circ} \mathrm{C}\right.$ lower than the fuel temperature) with temperature gradients of only $\sim 2^{\circ} \mathrm{C}$. The passive $\mathrm{SiC} \mathrm{TMs}$ will be used to confirm the irradiation temperatures [10]. 

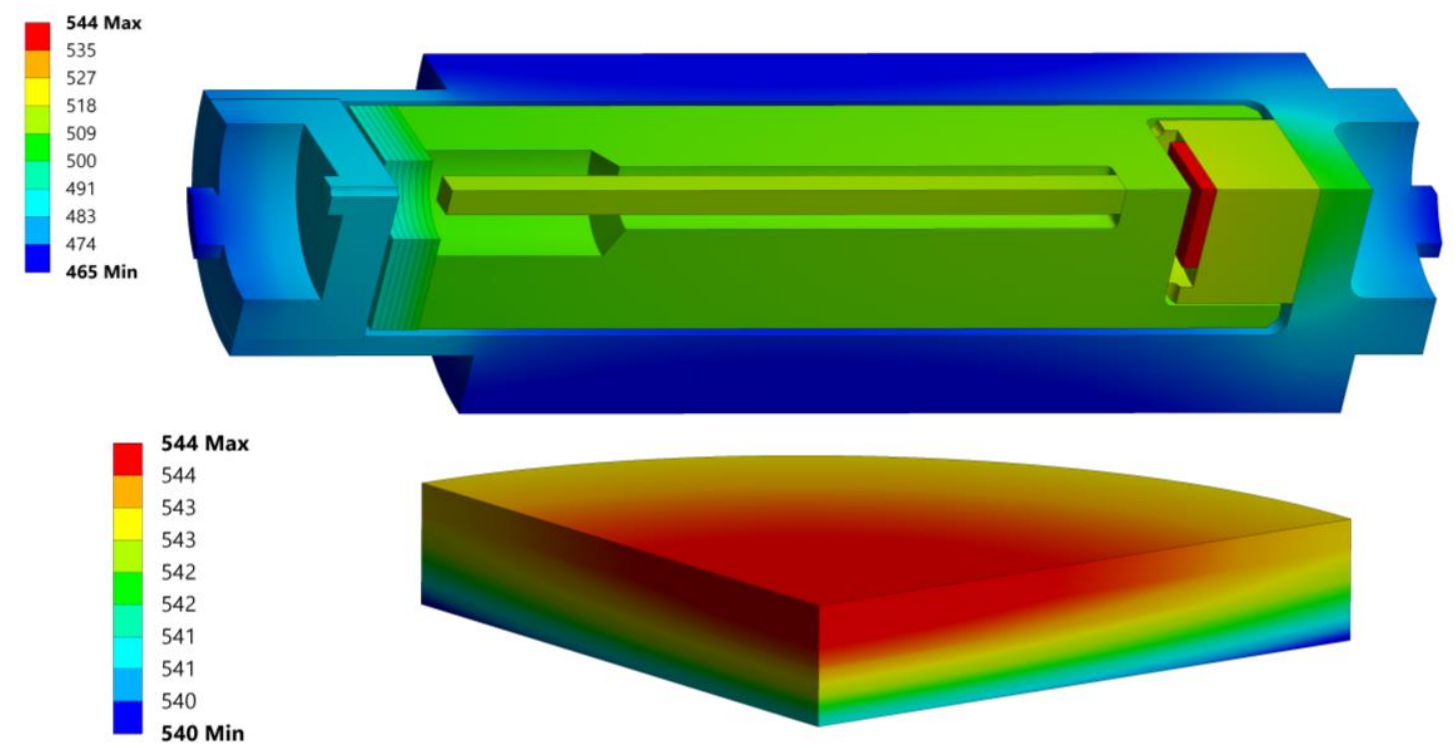

Figure 7. Predicted temperature contours (in ${ }^{\circ} \mathrm{C}$ ) for a $\mathrm{U}_{3} \mathrm{Si}_{2}$ disk specimen in position RAS 123 at the end of 4 cycles of irradiation. Results show the capsule assembly (top) and the fuel specimen (bottom).

Figure 8 shows the average fuel and TM temperatures for all $\mathrm{U}_{3} \mathrm{Si}_{2}$ fuel specimens at beginning of cycle (BOC) and end of cycle (EOC) for cycles 1, 4, and 12. Temperatures for $\mathrm{UO}_{2}$ specimens are very similar, as the fuel specimens have similar geometries and enrichments, and the MiniFuel experiment vehicle was specifically designed to be insensitive to variations in fuel heat load. The fuel temperature generally remains within the desired range of $450-550^{\circ} \mathrm{C}$ for most of the experiment. Fuel temperatures increase from BOC to EOC due to the withdrawal of the HFIR control plates. This increases the neutron and gamma flux in the reflector positions. For the MiniFuel experiments, the primary effect is an increase in gamma heating rates in the structural materials. There is also a small increase in fuel temperatures from Cycles 1-12 due to increases in fission heating resulting from breeding of plutonium isotopes (see Figure 6). 

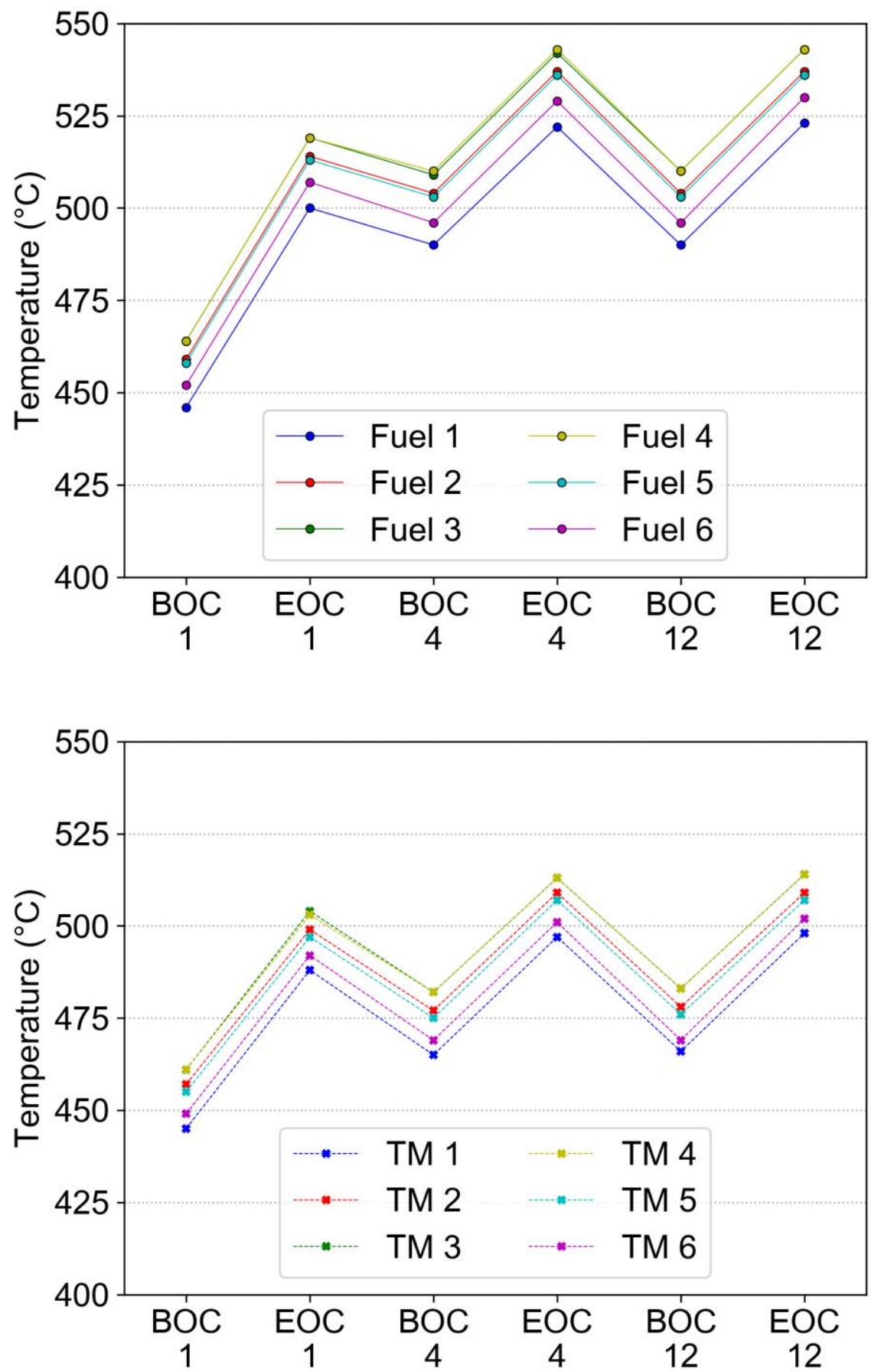

Figure 8. Calculated variations in the average $\mathrm{U}_{3} \mathrm{Si}_{2}$ disk fuel temperatures (top) and TM temperatures (bottom) at beginning of cycle (BOC) and end of cycle (EOC) for cycles 1, 4, and 12. 


\section{EXPERIMENT FABRICATION}

As shown in Table 1 above, 12 fueled capsules were assembled. The parts layout for one capsule is shown in Figure 9. The components include a single fuel disk specimen $\left(\mathrm{UO}_{2}\right.$ shown), the capsule itself, and the capsule's endcap, cup, TM, filler, and insulators. The signed subassembly fabrication request forms are provided in Appendix A. All capsule components were dimensionally inspected and cleaned according to HFIR-approved procedures, drawings, and sketches.

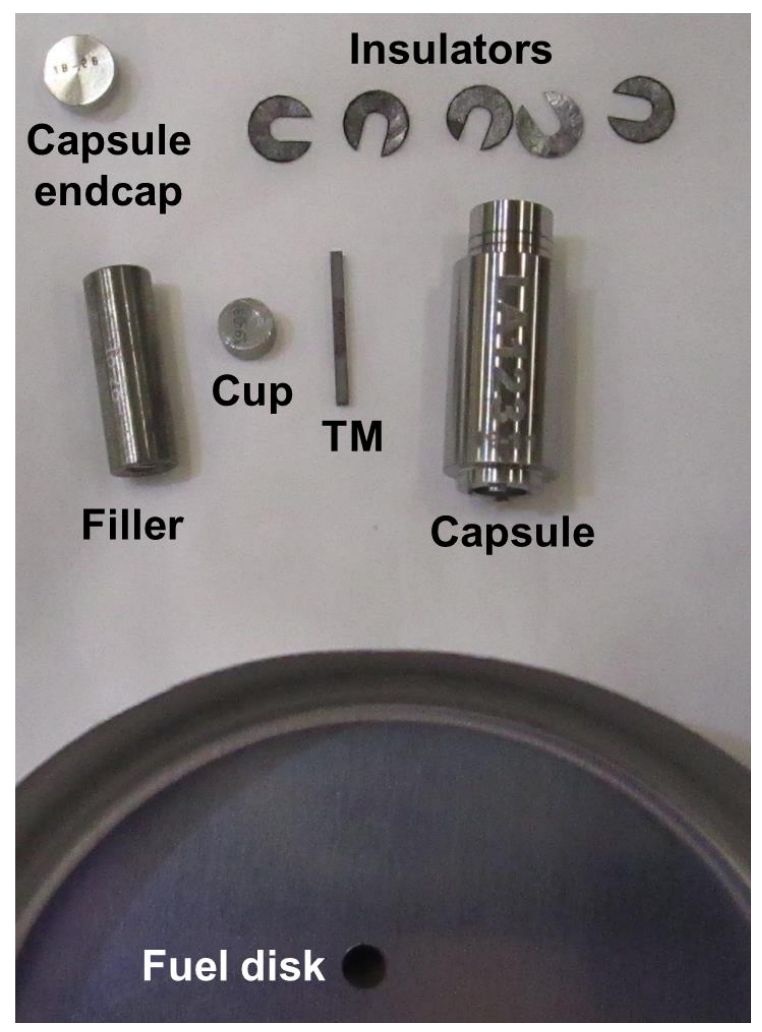

Figure 9. Components for one $\mathrm{UO}_{2}$-fueled capsule.

The fuel disks are loaded into the cup inside a custom bottom loading fixture as shown in Figure 10. After placing the fuel specimens in the cup, the filler is placed on top of the cup assembly, and the top loading fixture is used to apply pressure to the filler while it is flipped upside down, as shown in Figure $11(\mathrm{a}, \mathrm{b})$. The capsule is then flipped upside down and placed over the filler, as shown in Figure 11(c). The capsule is turned upright, and pressure is applied again with the top loading fixture to keep the internal components from moving. Figure 12 shows an upright capsule after inserting the TM (a), the insulators (b), and the endcap (c). Lines were engraved into the upper regions of the capsules to identify the location where each capsule should be punctured after irradiation, to measure fission gas release, and then cut open. 


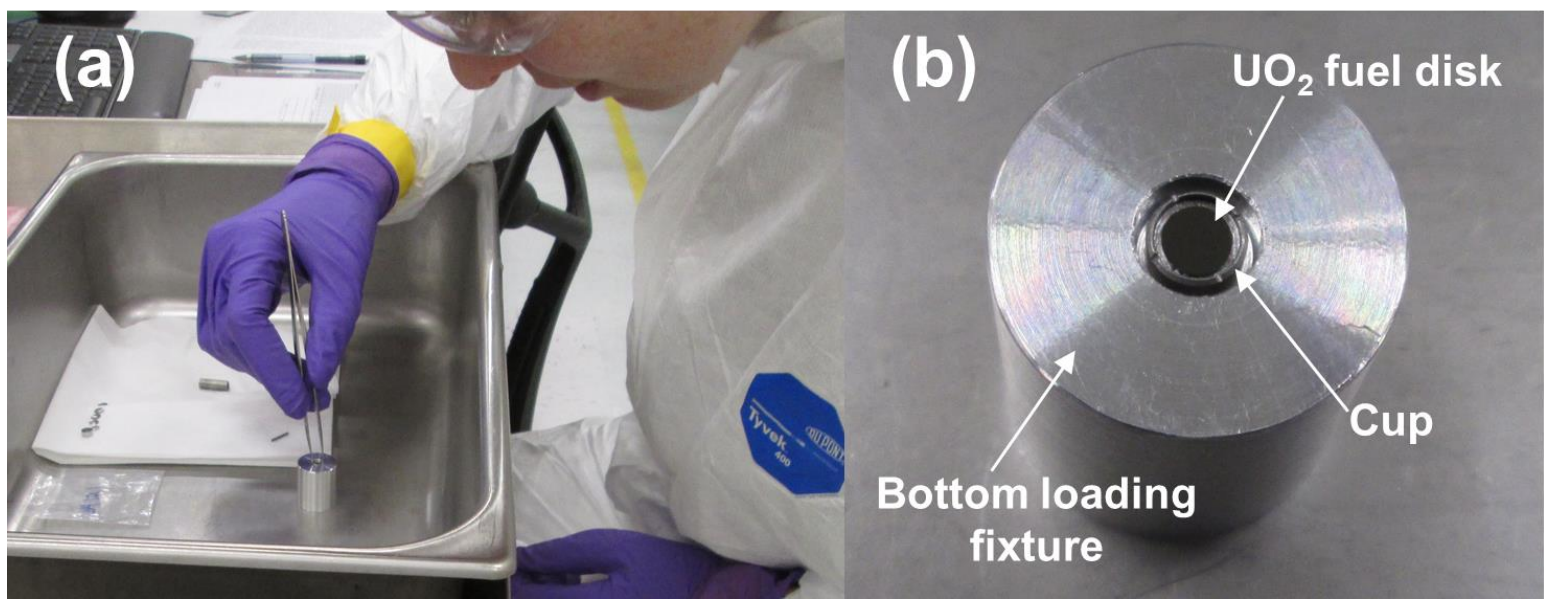

Figure 10. Loading of a $\mathrm{UO}_{2}$ disk specimen (a) into a cup inside the bottom loading fixture (b).

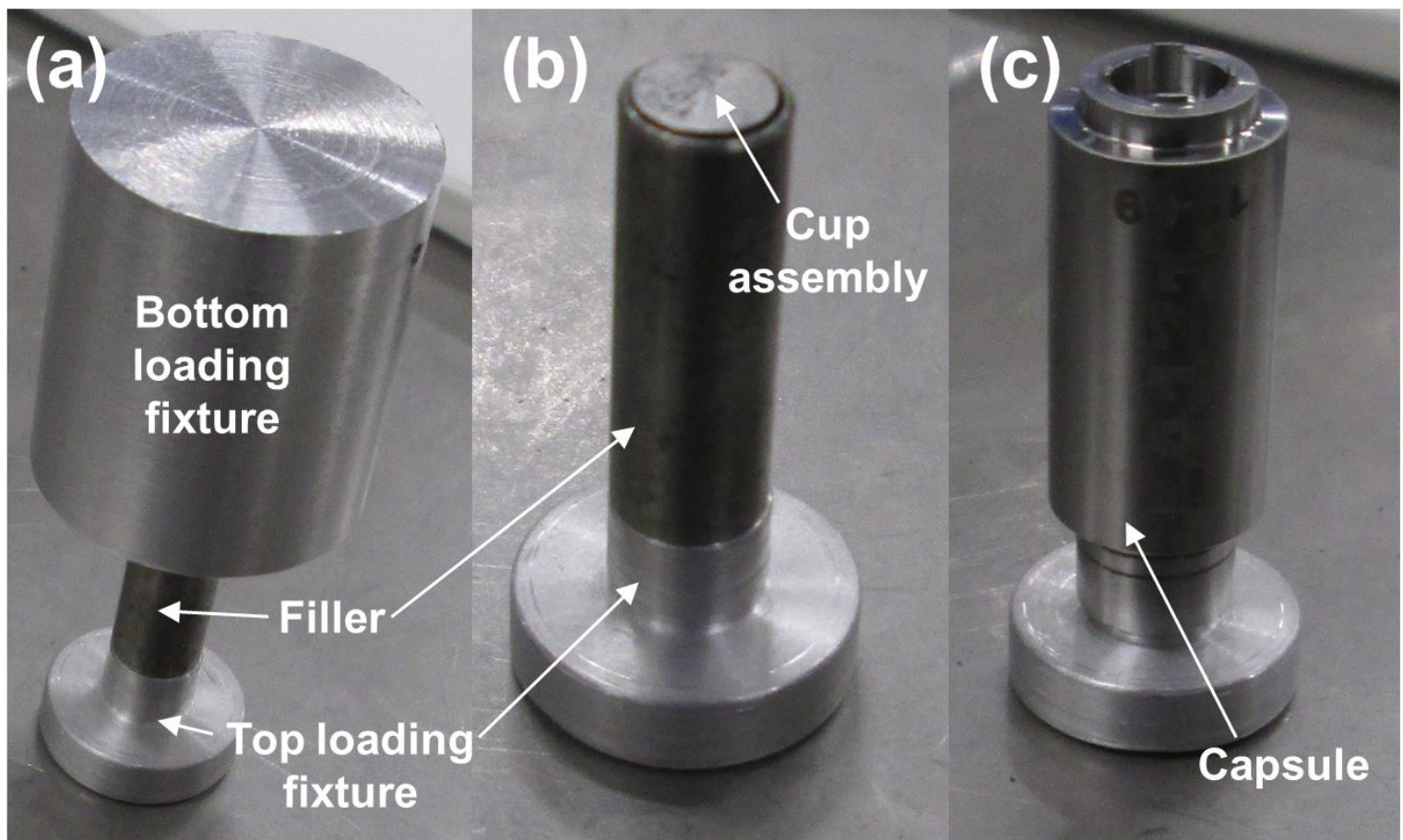

Figure 11. Filler placed over cup assembly and turned upside down while applying pressure with top loading fixture (a), bottom loading fixture removed (b), and capsule is turned upside down and placed over the tube and cup assembly (c). 


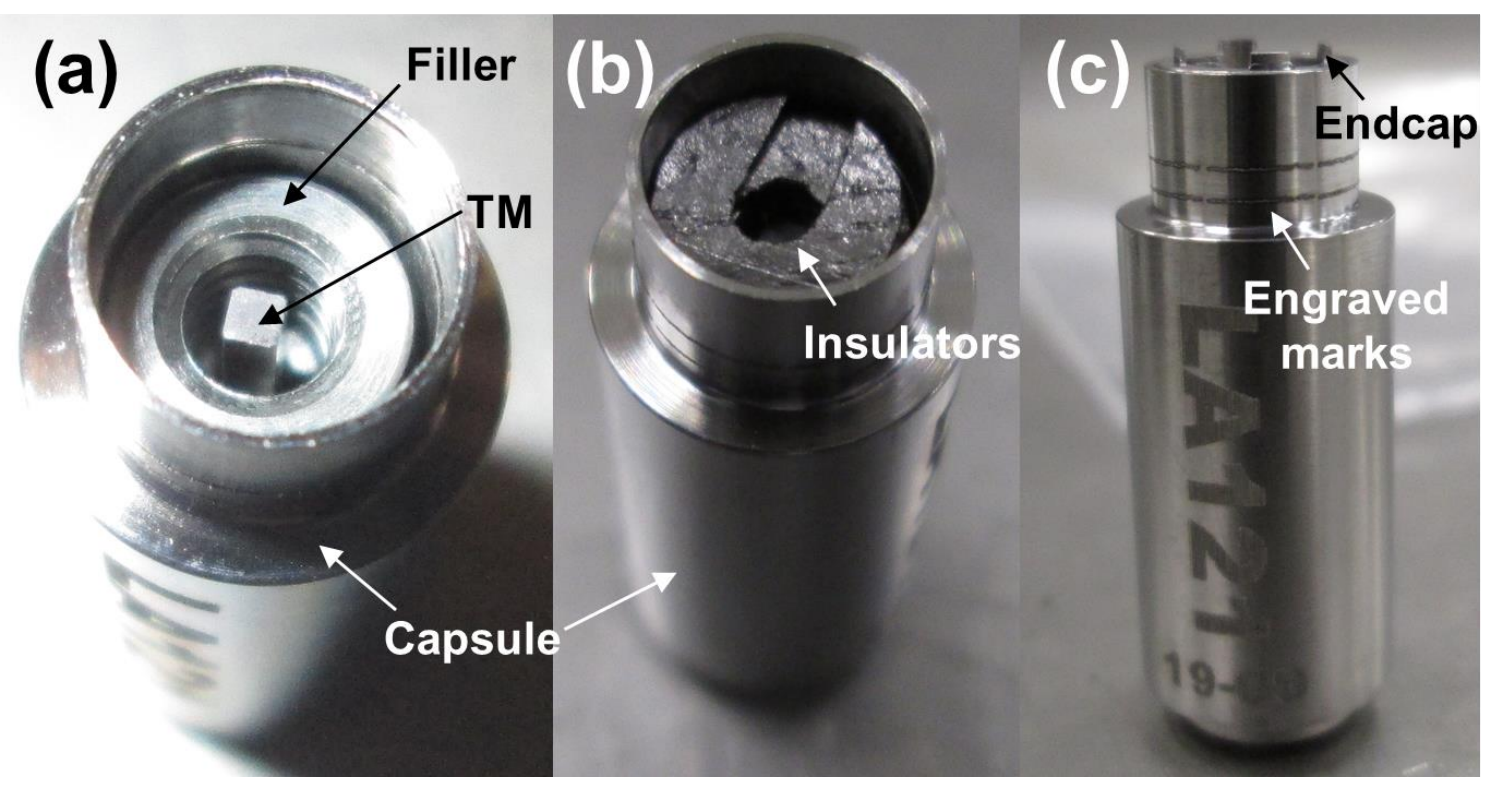

Figure 12. Loading TMs (a), insulators (b), and endcaps (c) into a capsule.

After the internal components were assembled, all capsule endcaps were welded to the capsule bodies using an electron beam weld (see Figure 13). The capsule assemblies were then placed inside sealed containers that were evacuated and backfilled with ultra-high-purity helium three times to ensure a pure environment. The containers were placed inside a glove box, which was also evacuated and backfilled with the same gas used in the sealed containers. Each capsule's end cap has a small hole that was seal-welded using a gas tungsten arc welding procedure. All welds passed visual examination. Each capsule was then sent for nondestructive examination, which included a bubble test and a helium leak test. All assemblies passed the nondestructive examination (see Appendix A).

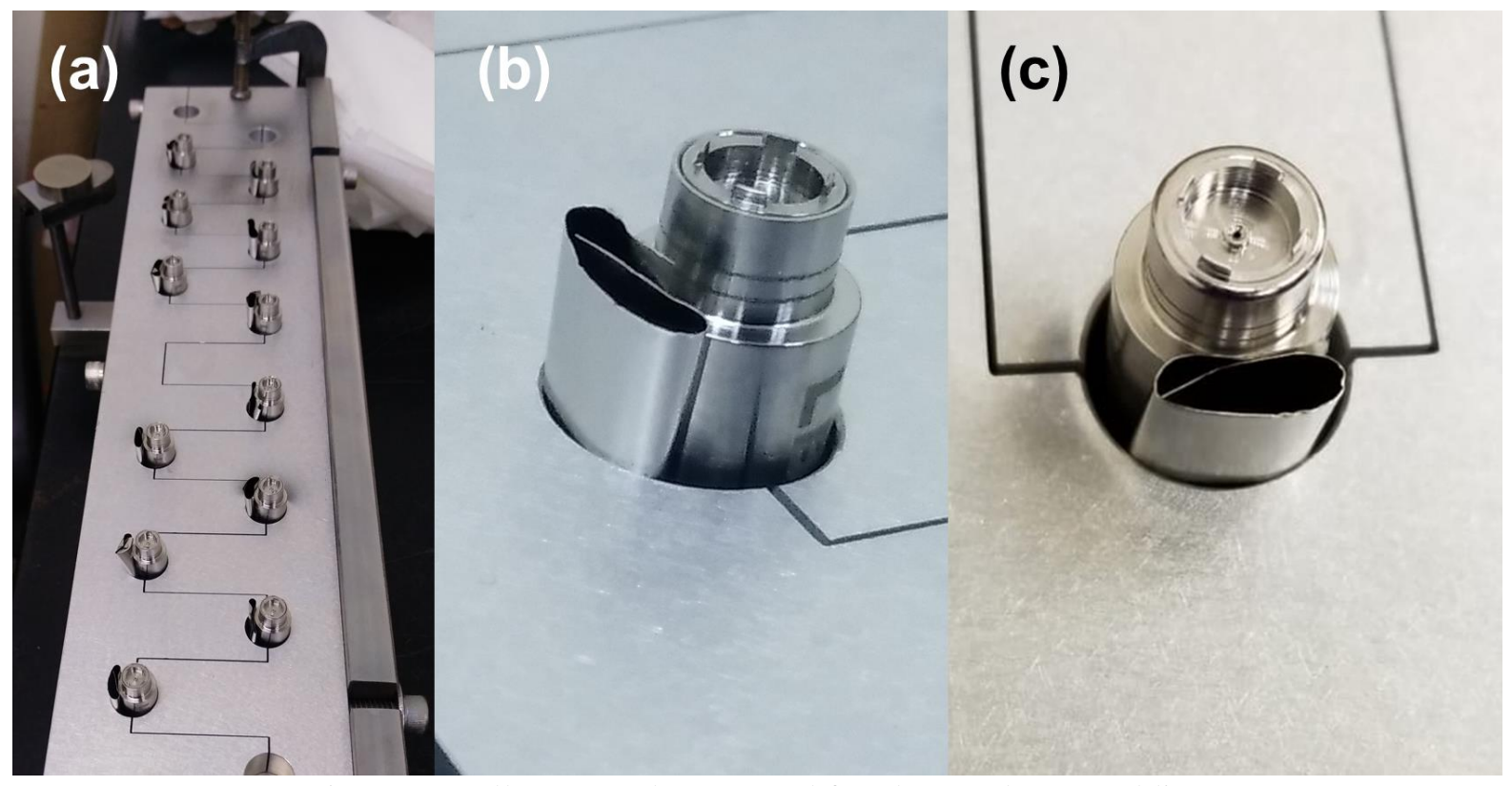

Figure 13. All 12 capsules prepped for electron beam welding (a); close-up views of a single capsule before (b) and after (c) welding. 


\section{PLANNED POST-IRRADIATION EXAMINATION}

The first target (LA01) will be irradiated to a nominal burnup of 8-10 MWd/kg U, which corresponds to 4-5 cycles of irradiation. After a few months of cooling, the LA01 target will be shipped to the Irradiated Fuels Examination Laboratory (IFEL) for disassembly in the late calendar year 2020 timeframe. The higher burnup target (LB02) is scheduled for 12 or more cycles of irradiation, which corresponds to a nominal burnup of $28 \mathrm{MWd} / \mathrm{kg} \mathrm{U}$ or higher. The final discharge burnup for LB02 will depend on results from LA01 and results from other $\mathrm{U}_{3} \mathrm{Si}_{2}$ irradiations. The tentative date for shipping LB02 is some time during calendar year 2022. After the targets are received at IFEL, they will be cut open with a slow-speed saw to extract the individual capsules. The capsules will then be punctured in a specially designed apparatus to collect the released ${ }^{85} \mathrm{Kr}$ fission gases. The ${ }^{85} \mathrm{Kr}$ gases will be frozen in cold traps, and then gamma counting of the traps will be performed to measure the ${ }^{85} \mathrm{Kr}$ content, and thus the fission gas release [8]. The the capsule endcaps will be cut using a slow-speed saw so that the TMs and fuel specimens can be extracted. The fuel will be transferred to separate facilities to measure mass and volume. Measurements will likely be taken using XCT [7], which will allow for determination of fuel swelling. Finally, the specimens will be prepared for microstructural characterization using optical and electron microscopy. 


\section{SUMMARY AND CONCLUSIONS}

This report summarizes the first successful fabrication of MiniFuel capsules loaded with monolithic ATF samples under AFC. $\mathrm{U}_{3} \mathrm{Si}_{2}$ and $\mathrm{UO}_{2}$ samples were successfully assembled into capsules, welded, nondestructively tested, and are now ready for insertion into the HFIR during cycle 487 (April 2020). These monolithic fuel disks will be evaluated post-irradiation to determine swelling, fission gas release, and microstructural evolution. This report describes the test matrix and the pre-irradiation specimen characterization, including pictures of the specimens and the capsule assembly process. One of the key challenges moving forward will be to choose the appropriate technique to accurately quantify the physical density of these small fuel samples so that fuel swelling can be accurately determined. The data that will be collected from this experiment will complement current integral tests of $\mathrm{U}_{3} \mathrm{Si}_{2}$ being performed in the Advanced Test Reactor and will ultimately inform fuel performance modeling of $\mathrm{U}_{3} \mathrm{Si}_{2}$ for light-water reactor applications. The inclusion of monolithic $\mathrm{UO}_{2}$ specimens in a MiniFuel experiment will provide the first opportunity to benchmark MiniFuel experiments against the large amount of $\mathrm{UO}_{2}$ fuel performance data that has been collected over many decades.

\section{REFERENCES}

1. Crawford, D. C. et al., "An approach to fuel development and qualification," Journal of Nuclear Materials, 371 (2007) pp. 232-242.

2. Petrie, C. M., J. R. Burns, A. M. Raftery, A. T. Nelson and K. A. Terrani, "Separate effects irradiation testing of miniature fuel specimens," Journal of Nuclear Materials, 526 (2019) pp. 151783.

3. Petrie, C. M., J. Burns, R. N. Morris and K. A. Terrani, "Miniature Fuel Irradiations in the High Flux Isotope Reactor," In 40th Enlarged Halden Programme Group Meeting. 2017: Lillehammer, Norway.

4. Petrie, C. M., J. Burns, R. N. Morris and K. A. Terrani, "Small-Scale Fuel Irradiation Testing in the High Flux Isotope Reactor," In Water Reactor Fuel Performance Meeting 2017. 2017: Jeju Island, Korea.

5. Petrie, C. M. et al., Irradiation of Miniature Fuel Specimens in the High Flux Isotope Reactor, ORNL/SR-2018/844, Oak Ridge National Laboratory: Oak Ridge, TN (2018).

6. Abdul-Jabbar, N. M. and J. T. White, Processing and Characterization of U3Si2 at the MiniFuel Scale, LA-UR-19-23733, Los Alamos National Laboratory: Los Alamos, NM (2019).

7. Richardson, M. D., G. W. Helmreich, A. M. Raftery and A. T. Nelson, Resolution capabilities for measurement of fuel swelling using tomography, ORNL/SPR-2019/1071, Oak Ridge National Laboratory: Oak Ridge, TN (2019).

8. Raftery, A. M. et al., Development of a characterization methodology for post-irradiation examination of miniature fuel specimens, ORNL/SPR-2018/918, Oak Ridge National Laboratory: Oak Ridge, TN (2018).

9. Remschnig, K., T. Le Bihan, H. Noël and P. Rogl, "Structural chemistry and magnetic behavior of binary uranium silicides," Journal of Solid State Chemistry, 97 (1992) pp. 391-399.

10. Field, K. G., J. L. McDuffee, J. W. Geringer, C. M. Petrie and Y. Katoh, "Evaluation of the continuous dilatometer method of silicon carbide thermometry for passive irradiation temperature determination," Nuclear Instruments and Methods in Physics Research Section B: Beam Interactions with Materials and Atoms, 445 (2019) pp. 46-56. 



\section{APPENDIX A. FABRICATION DOCUMENTATION FOR EXPERIMENTS}


Target ID:

Irradiation Conditions

Irradiation Location $(\mathbb{R}, A)$

Number cycles

First Cyclo Gool

Fill Gas

Holder assembly drawing

Holder Assembly
Irradiation Temperature
LA01

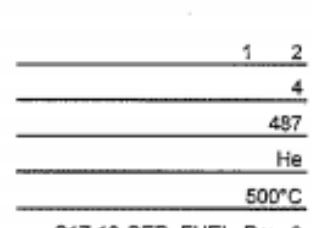

S17-13-CER.FUEL, ReV. 2

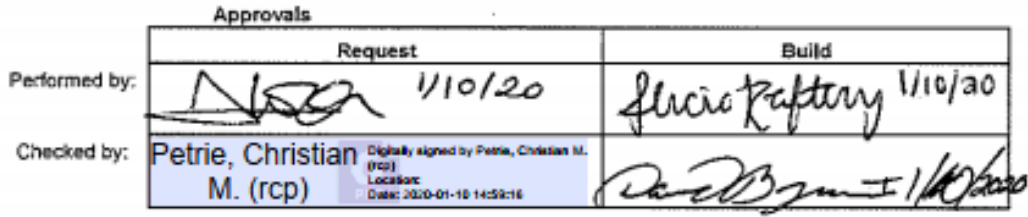
Drowing Rev. Part \begin{tabular}{l|l|l|l|}
\hline S17-14-CER_FUEL & 2 & 1 \\
\hline S17-14-CER FUEL & 2 &
\end{tabular} \begin{tabular}{ll|l|l|l} 
S17-14-CER_FUEL & 2 & 2 \\
\hline S17-13-CER_FUEL & 2 & \\
\hline
\end{tabular} S17-13-CER FUEL 2 - 3

End cap

Tube

Thermometry

Insulator disks (list total \# and mass)

Disk fuel dish

Cisk fuel specimen

Disk fuel specimen \begin{tabular}{|c|c|c|c|c|c|}
\cline { 2 - 7 } & \multicolumn{5}{|c|}{ Component IDs for each hoider ID } \\
\hline LA121 & LA122 & LA123 & LA124 & LA125 & LA126 \\
\hline
\end{tabular}

(1)

\begin{tabular}{|c|c|}
\hline Materlal & MAT \\
\hline Ti-GAN4V & 21 \\
\hline Ti-6AN4V & 20 \\
\hline Moly & 20 \\
\hline SiC & 20 \\
\hline Grád & 18 \\
\hline Moly & 20 \\
\hline UO2 & 20 \\
\hline USSI2 & 20 \\
\hline
\end{tabular}

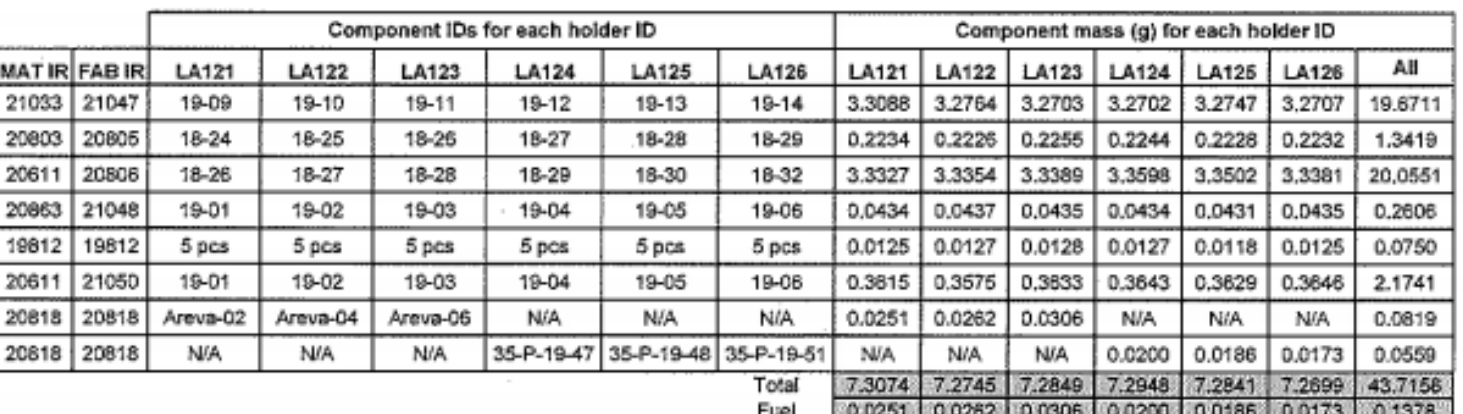

Capsule fabrication request sheet for target LA01. 


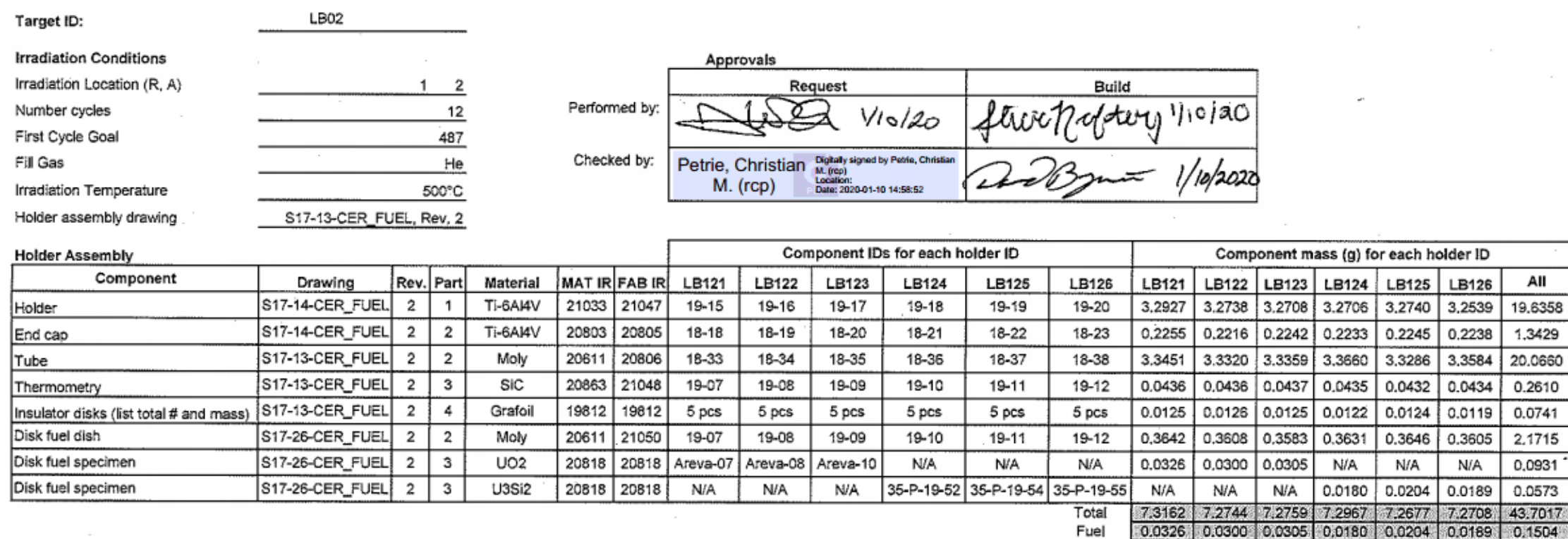

Capsule fabrication request sheet for target LB02. 


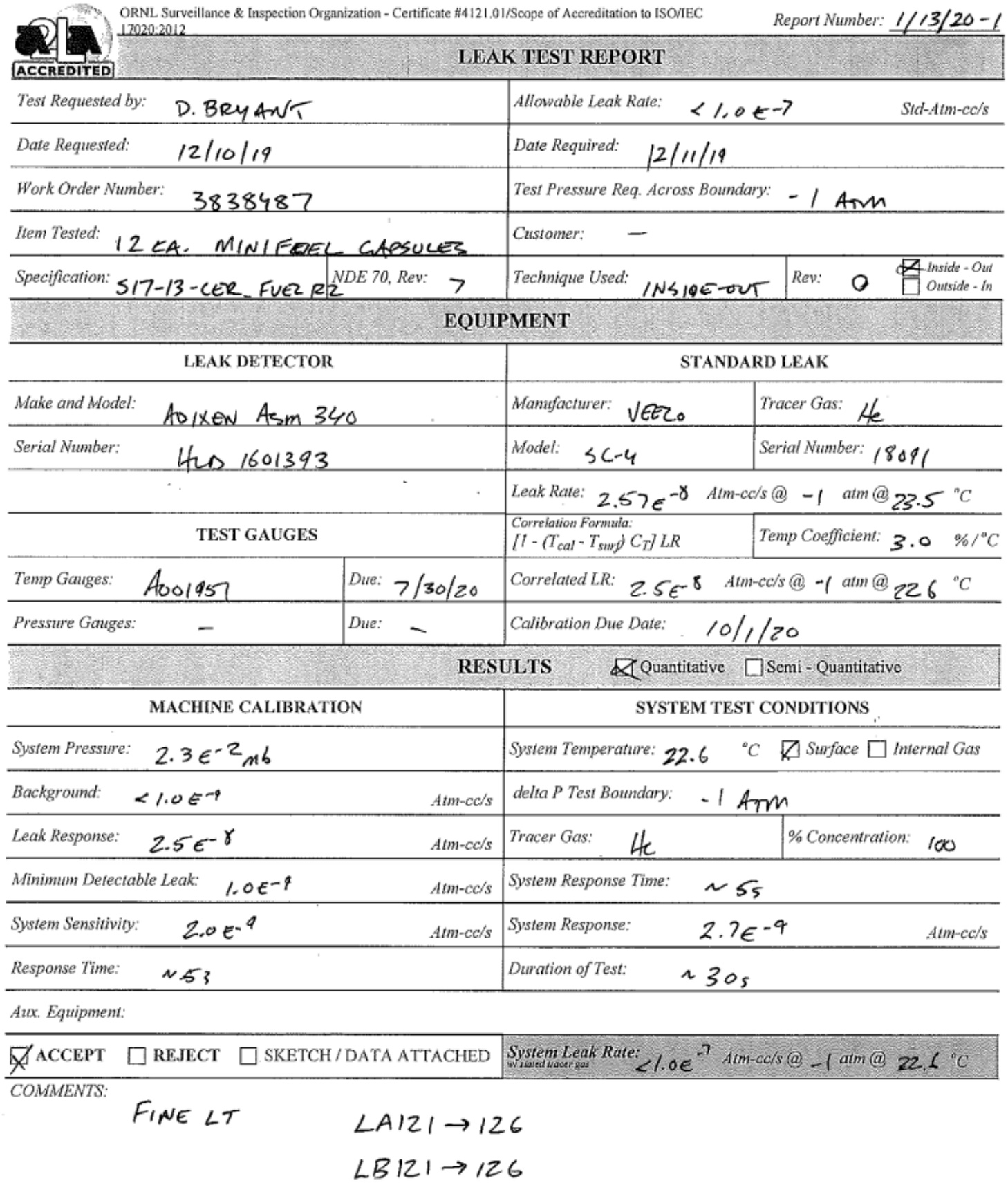

Test Conducted By:
E.VAOA2

Helium leak testing results for all capsules 


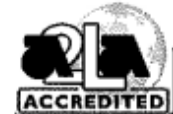

\begin{tabular}{|c|c|}
\hline Test Requested by: D.BRYANT & Customer: \\
\hline Date Requested: $12 / 10 / 19$ & Date Required: $12 / 11 / 19$ \\
\hline Work Order Number: $\quad 3838487$ & \begin{tabular}{|l|l|} 
NDE 70, Rev: 7 & Tech, NDE 70-BT Rev: 0 \\
\end{tabular} \\
\hline Item Tested: 12 EA. MINI FUEZ CAPSULES & Test Pressure Required: - I Am \\
\hline Specification: $S 17-13-C E R$ - FUE $R, 2$ & Inspection Criteria: No BUBBLes e $2 \mathrm{MIN}$ \\
\hline Technique Used: VA工 BOX & Liquid Media Used: ImmensIT um 200 e $20 \%$ su \\
\hline Test Gas Used: & Liquid Applicator Type: IMmers/or \\
\hline Inspection Light Intensity: $>100 \mathrm{FC}$ & Post Cleaning Method: DI RINSE - DRW \\
\hline
\end{tabular}

\begin{tabular}{|c|c|c|c|c|c|c|c|}
\hline \multicolumn{4}{|c|}{ Dinect Pressure T echinique } & \multicolumn{4}{|c|}{ Vacuam Pressuie Teunique $\$$} \\
\hline \multicolumn{8}{|c|}{ Component Limits of Test: } \\
\hline \multicolumn{2}{|c|}{ Component Test Site } & 00 & & \multicolumn{4}{|c|}{ Component Installation Site } \\
\hline \multicolumn{4}{|c|}{ Gauges } & \multicolumn{2}{|c|}{ Test Pressure } & \multicolumn{2}{|c|}{ Temperature } \\
\hline \multirow[t]{2}{*}{ Mfg } & ID No & $\begin{array}{l}\text { Calibration } \\
\text { Date }\end{array}$ & Range & Beginning & End & Beginning & End \\
\hline & $A 002126$ & $8 / 26 / 19$ & $0.30 " \mathrm{Hs}$ & $15 " \mathrm{Hg}$ & $15^{\prime \prime} \mathrm{Htg}$ & - & - \\
\hline
\end{tabular}

Temperature Measuring Device

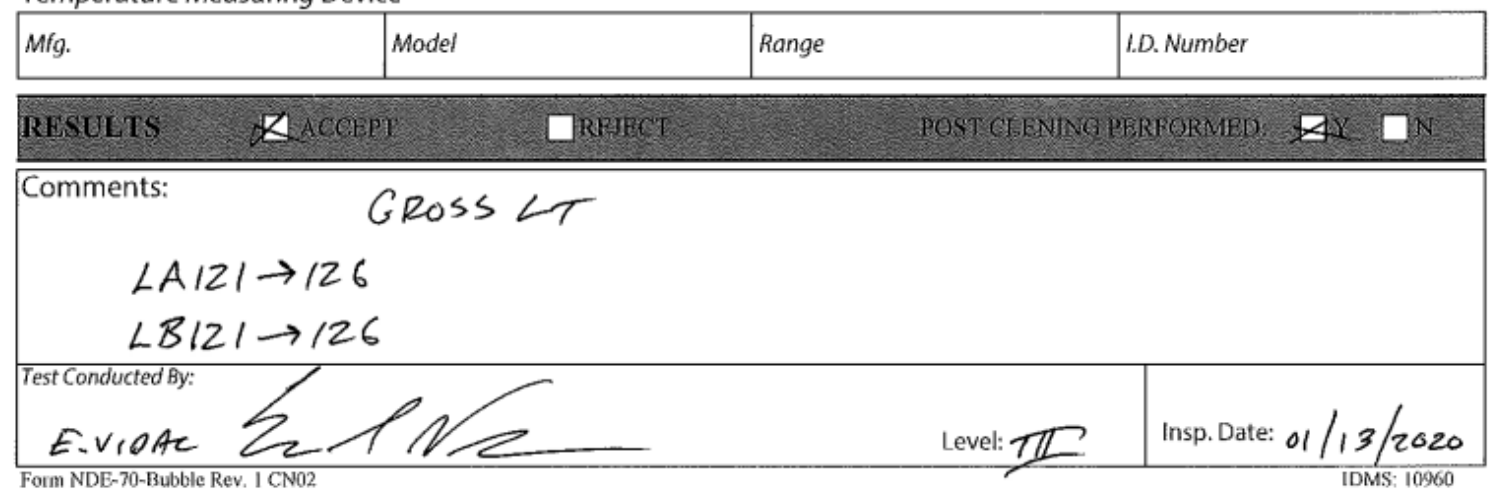

Bubble testing results for all capsules 